\title{
Rhomboid flap: An option to medial canthal reconstruction
}

\section{Rafael Corredor-Osorio}

\author{
Department Oculoplastic and Orbit, Centro Ocular Corredor Oftalmología Especializada, Valera (Trujillo), Venezuela.
}

Corresponding author: Dr. Rafael Corredor-Osorio, E-mail: raficorredor@yahoo.com

\begin{abstract}
Medial canthal defects after wide local excision of basal cell carcinoma can range from small to medium size which can be reconstructed by using full thickness skin-grafts or defect local flaps. This report describes the case of 51-yearold woman with a medial canthal tumor. The large defect after of excision was successfully reconstructed with local rhomboid flap. The result cosmetic was highly satisfactory. Local rhomboid flap reconstruction is a safe, rapid and practical technique for skin defects in the canthal medial region after tumor excisions.
\end{abstract}

Key words: Rhomboid flap, Reconstruction, Medial canthal, Skin defects

\section{INTRODUCTION}

The medial canthus is the second most common location for periorbital basal cell carcinomas [1]. The medial canthal region represents a multicontoured area with great variation in skin thickness, color, texture, and appendage density, and it includes contributions from the orbital and tarsal portions of the upper and lower eyelids, the nasal sidewall, the glabella [2], brow, cheek [3], the bony attachments of the medial canthal tendon, the lacrimal puncta, and arteriovenous and neural bundles that supply and innervate the region [4]. The surgical medial canthus is much larger than the anatomical medial canthus, and extends vertically into the sub-brow region, medially to the side of the nose and close to the midline, and inferiorly onto the cheek [3].

After tumour excision the resultant defect can be closed by a variety of methods depending on its size, location, depth, and patient preference [4]. Limberg defined the rhomboid flap and presented his studies in English in 1963. It is basically a parallelogram with two angles of $120^{\circ}$ and two of $60^{\circ}[5,6]$. These angles, of course, can be modified depending on the shape of the lesion or defect. All sides of the rhomboid and all sides of the flap are equal. As many as four flaps can be raised from one rhomboid, if required [5]. In 1962, Claude Dufourmentel modified the rhomboid flap. In his design, the distal border of the flap is placed on the line that bisects the angle between the short diagonal of the rhomboid defect and its adjacent side; the acute angle of the flap is still $60^{\circ}[6,7]$ Webster described another modification that combined a 30o transposition flap with an M-plasty to repair rhomboidal defects [6]. Quaba proposed a rhomboid flap in1987 to coverage circular defects [7].

After wide local excision of basal cell carcinoma can range from small to medium size which can be reconstructed by using a full thickness skin grafts or defect local flaps.

This report describes the case of 51-year-old woman with a medial canthal basal cell carcinoma. The large skin defect after excision was reconstructed with local rhomboid flap (Limberg flap), and here we showed the illustration of the respective technique.

\section{CASE REPORT}

A 51-year-old female patient complained of a left medial canthal lesion that had increased slowly in size 
over the past two years. At the time of the patients visit, the nodule measured $1.2 \times 0.9 \mathrm{~cm}$. It was well demarcated and had a black pigmented nodule. The appearance was typical of a nodular basal cell carcinoma (Fig. 1). Her visual acuity and eyelid movements were normal.

\section{OPERATIVE PROCEDURE}

The rhomboid consists of two equilateral triangles placed base to base. For medial canthal defects there are two possible rhomboid flaps. These are constructed as follows. A line of the same length as the bases of the triangles is drawn horizontally across the nose from the base of the triangles. Two vertically oriented lines from the tip of the horizontal line are drawn at an angle of 60 degrees. These lines are the same length and parallel to the side of the rhomboid. The upper flap is used because of the greater laxity of the upper nasal skin. The resultant scar is also more easily hidden. The flap is oriented parallel to the lines of maximal extensibility, allowing the donor site and defect to be closed with the minimum tension. The lines of maximal extensibility are perpendicular to the horizontally oriented relaxed skin tension lines on the bridge of the nose. The scar from closure of the flap's donor site is hidden in a relaxed skin tension lines [1].

The procedure is performed under local anaesthesia. The tumor at the medial canthal region is measured and an adequate rhomboid flap is marked on the skin around the lesion, before the subcutaneous injection of $50 \%$ bupivacaine $0.5 \%$ and $50 \%$ lignocaine $2 \%$ with epinephrine (concentration, 1 in 200.000) and then apply firm pressure for 3 minutes. Flap preparation begins with drawing a diamond, with internal angles of 60 and 120 degrees, around the defect resulting from the resection (Fig. 2). An incision is then made through the skin and subcutaneous tissue. The flap boundaries are cut with a scalpel, dissected, and mobilized with blunt scissors beneath the flap and across the dorsum of the nose (Fig. 3). The lesion was excised with a $3 \mathrm{~mm}$ free margin (Fig. 4). The subcutaneous tissue at the base of the flap and the edges of the defect are undermined in the subdermal plane to minimize the tension at the suture lines. Gentle cautery is performed under the flap. The flap was elevated and transposed over the defect (Figs 5 and 6). The undersurface of the flap is anchored to periosteum to reform the concave contour of the medial canthus with $6 / 0$ vicryl sutures.Interrupted buried $6 / 0$ sutures are used to approximate the dermis and subcutaneous tissue and close the defect completely (Figs. 7A, 7B and 8). A bolster is applied

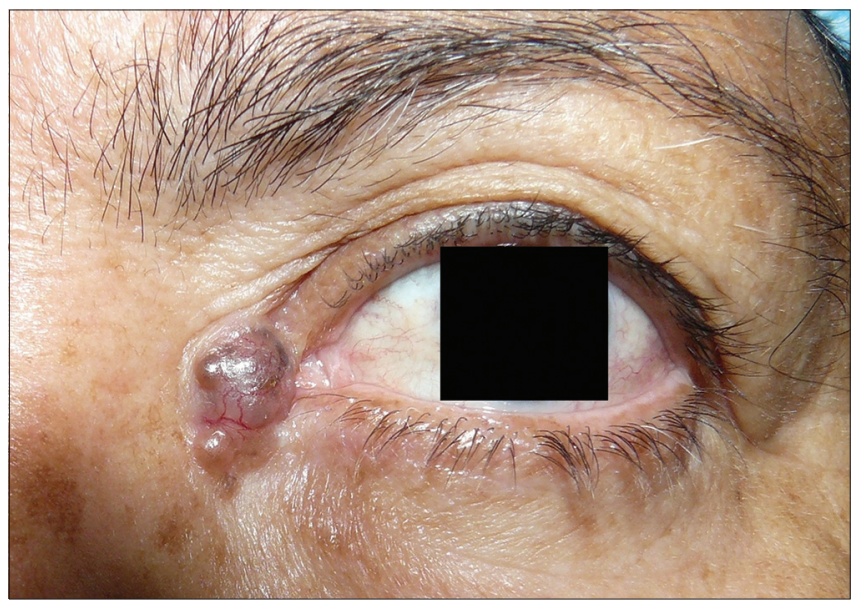

Figure 1: Left medial canthal basal cell carcinoma.

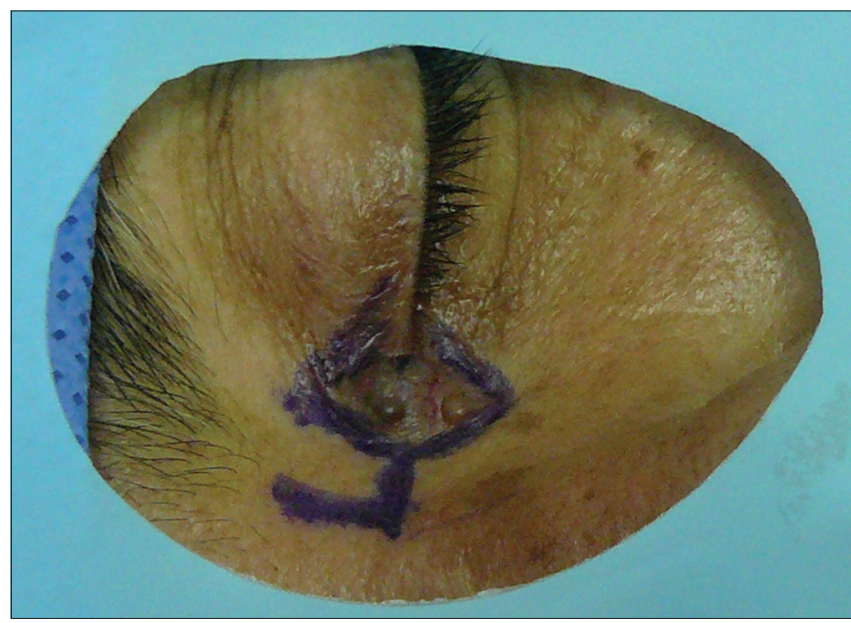

Figure 2: Rhomboid flap designed.

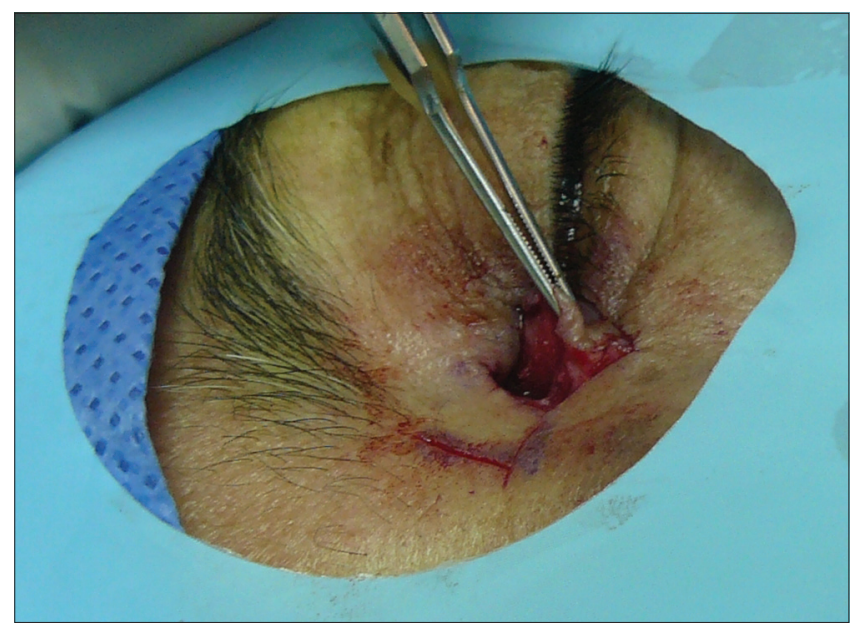

Figure 3: The tumor was dissected with $3 \mathrm{~mm}$ free margin. 


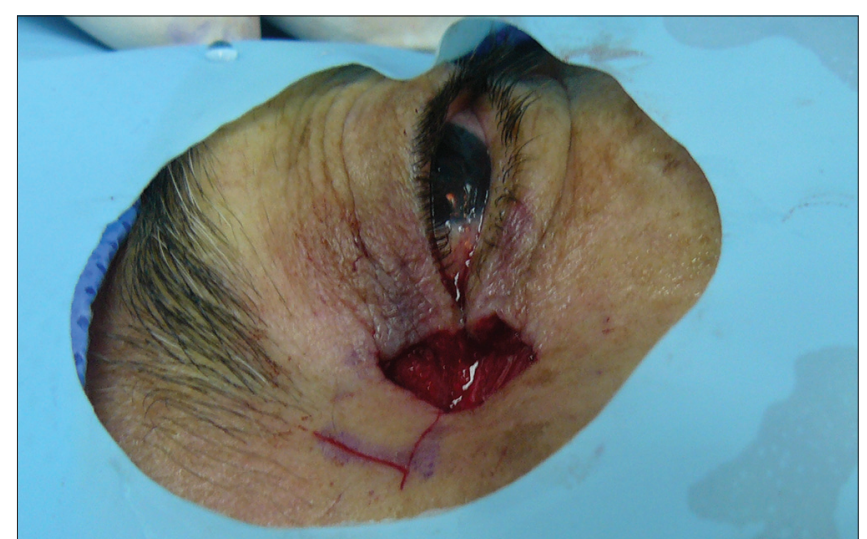

Figure 4: Medial canthal defect.

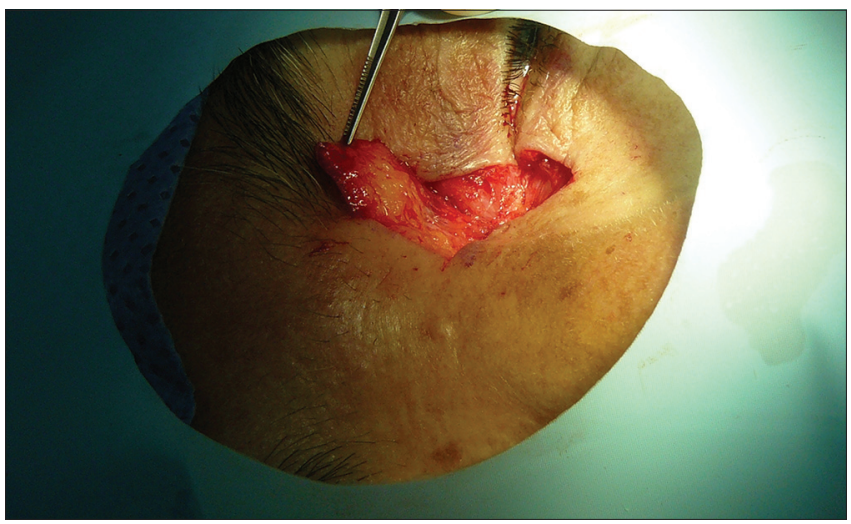

Figure 5: A rhomboidal flap was fashioned.

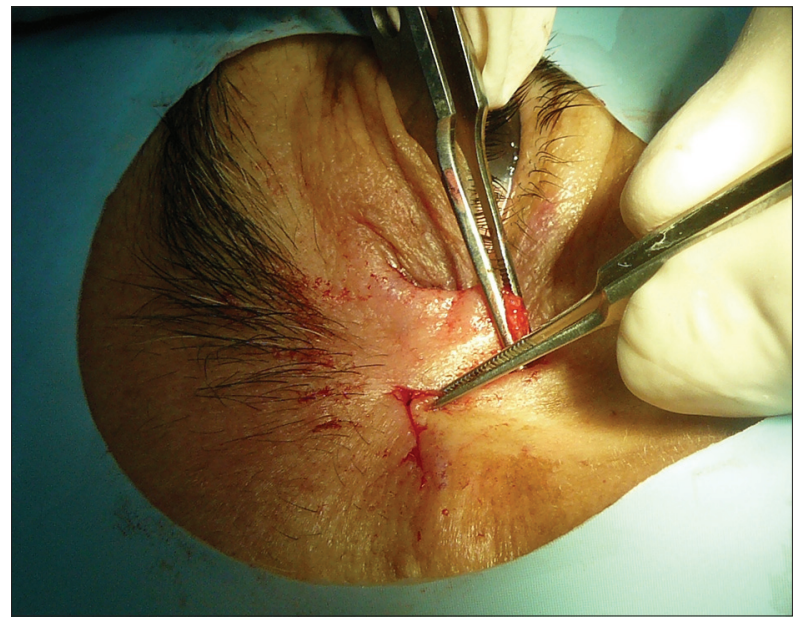

Figure 6: Rotation of flaps into donor site.

over flap to push the skin gently against the recipient bed. The dressing and bolster are removed in 5 days. Topical antibiotic ointment is applied twice daily for 7 days. The sutures are removed in 7 days (Fig. 9). Histopathological examination of the tumor revealed nodular basal cell carcinoma conformed that the margin was free of tumor.
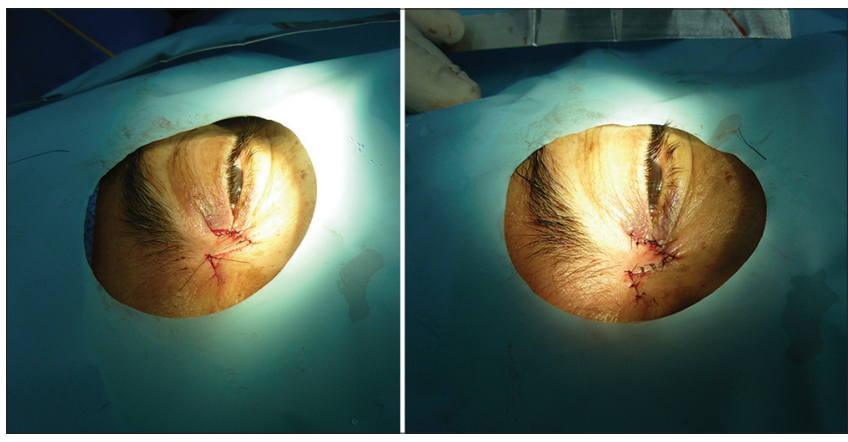

Figure 7: Closure of secondary defect. A) Partially sutured. B) Complete Sutured.

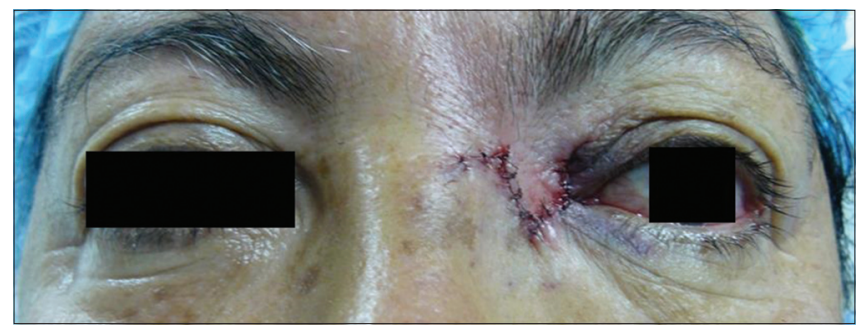

Figure 8: Perioperative appearance of the medial canthal region.

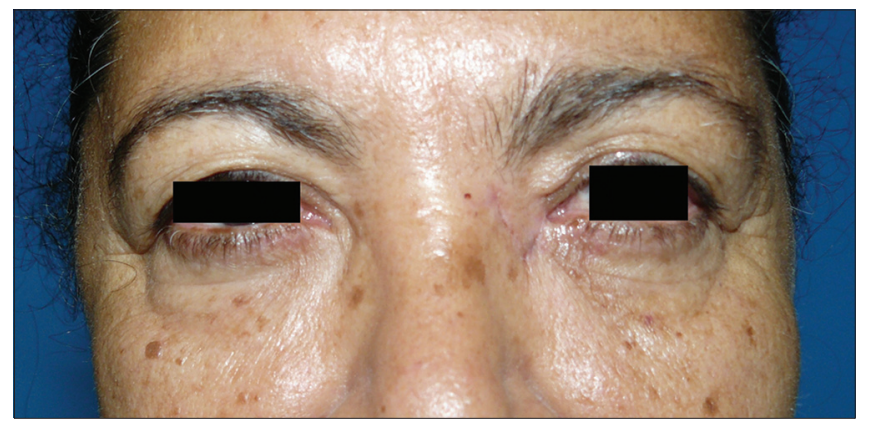

Figure 9: Two weeks follow-up results.

\section{DISCUSSION}

Face represents complete personality of human being. Therefore, adequate cosmetic correction of facial defects arising due to various injuries and lesions is very important [8]. The rhomboidal flap can be used at any region on the body surface, and is widely on facial and breast reconstruction, neurosurgery, ophthalmology and proctology. When used for surgical procedures for correcting facial defects, the rhomboidal flap produces good functional and aesthetic results, particularly when scars are positioned at the junction of the aesthetic units of the face [9]. Reconstructive planning in the medial canthal region is complex due to the variety of structures that can be involved, the unique contours, and the multitude of techniques available [10]. 
The surgical dilemma comes from the quality of the skin removed and the thickness of the tissue available for replacement. Several techniques are used to repair medial canthal defects: Simple laissez faire $[11,12]$, free full thickness, skin grafts $[1,11]$, rotational flap [4], glabellar flap [3], glabellar bilobed flap [11,12], bipalpebral sliding flaps [13], upper eyelid myocutaneous flap $[14,15]$, islands flaps, tunnelled forehead flaps [16] V-Y advancement flaps [4], and rhomboidal flaps $[1,9]$,

The rhomboid flap is a flap of skin and subcutaneous tissue that is rotated around a pivot point into an adjacent defect [1]. It has special application for eyelid, floor of nose, alar rim and chin defects. It is proposed that the rhomboid (Limberg) flap, single or multiple, can be applied widely with extreme safety and good cosmetic results [5]. The rhomboid flap has a low rate of complications as epitheliolysis with the partial necrosis of the flap, hematoma, bacterial infection and may occur dog ears [9].

This report shows that the rhomboid flap is an effective technique for medial canthal reconstruction. Its minimally invasive, quick to perform, and suitable to be easily performed in a single stage under local anesthesia. The flaps donor site is closed over the bridge of the nose the resultant scar is hidden in a relaxed skin tension line. The rhomboid flap provides the rotation of adjacent tissue to the defect with the same color, skin texture and thickness, resulting in excellent cosmetic outcomes.

\section{CONSENT}

The examination of the patient was conducted according to the Declaration of Helsinki principles written informed consent was obtained from the patient for publication of this article and any accompanying image.

\section{REFERENCES}

1. Ng SG, Inkster CF, Leatherbarrow B. The rhomboid flap in medial canthal reconstruction. Br J Ophthalmol. 2001;85:556-9.

2. Perry JD, Taban M. Superiorly based bilobed flap for inferior medial canthal and nasojugal fold defect reconstruction. Ophthal Plast Reconst Surg. 2009;25:276-9.

3. Maloof AJ, Leatherbarrow B. The glabellar flap dissected. Eye. 2000;14:597-605.

4. Behroozan DS, Goldberg LH. Upper eyelid rotation flap for reconstruction of medial canthal defects. J Am Acad Dermatol. 2005;53:635-8.

5. Chasmar LR. The versatile rhomboid (Limberg) flap. Can J Plast Surg. 2007;15:67-71.

6. Aydin OE, Tan O, Algan S, Kuduban SD, Cinal H, Barin EZ. Versatile use of rhomboid flaps for closure of skin defects. Eurasian J Med. 2011;43:1.

7. Tamborini F, Cherubino M, Scamoni S, Frigo C, ValdattaL. A modified rhomboid flap: The "diamond flap". Dermatol Surg. 2012;38:1851-5.

8. Gandevivala A, Shah DH, Sidana S, Khan A. Modified thomboidal flap to reconstruction of defect of cheek after excision of basal cell carcinoma. J Contemp Dent. 2016;6:154-6.

9. Di Santis ÉP, Elias BLF, Andraus EM, Mandelbaum SH. Rhomboid Flap: An Option to Many Anatomical Regions. J Adv Plast Surg Res. 2015;1:14-8.

10. Czyz CN, Cahill KV, Foster JA, Michels KS, Clark CM, Rich NE. Reconstructive options for the medial canthus and eyelids following tumor excision. Saudi J Ophthalmol. 2011;25:67-74.

11. Mehta JS, Olver JM. Infraglabellar transnasal bilobed flap in there construction of medial canthal defects. Arch Opbthalmol. 2006;124:111-5.

12. Sullivan TJ, Bray LC. The bilobed flap in medial canthal reconstruction. Aust NZ J Ophthalmol. 1995;23:42-8.

13. Adenis JP, Serra F. Bipalpebral sliding flap in the repair of inner or outer canthal defects. Br J Ophthalmol. 1986;70:135-7.

14. Han J, Known ST, Kim EC. Medial and lateral canthal reconstruction with and orbicularis oculi myocutaneous island flap. Arch Plast Surg. 2015;42:40-5.

15. Sarah A, Fréderic L, Raphael L. Potential use of the Upper Eyelid Myocutaneous Flap in the Reconstruction of Full-thickness Defects of the Medial Canthus. Surgery Curr Res. 2014;4:182.

16. Cecchi R, Fancelli L, Troiano M. Island flaps in the repair of medial canthus: Report of 8 cases. Dermatol Online J. 2013;19:18576.

Copyright by Rafael Corredor-Osorio, et al. This is an open access article distributed under the terms of the Creative Commons Attribution License, which permits unrestricted use, distribution, and reproduction in any medium, provided the original author and source are credited.

Source of Support: Nil, Conflict of Interest: None declared. 